\title{
Decision Tree Analysis of Job Stress and Satisfaction of Foreign Construction Laborers in Korea
}

\author{
Yoonseok Shin \\ Dept. of Plant·Architectural Engineering, Kyonggi University, Suwon, Republic of Korea \\ shinys@kgu.ac.kr
}

\begin{abstract}
With the aging of the existing construction workforce and the reluctance of young manpower to enter the construction field due to it being one of the so-called " $3 \mathrm{D}$ " (Dirty, Dangerous and Difficult) industries, the number of foreign laborers employed in Korean construction industry has been on the rise. As construction jobs involve high job intensity and the risk of safety accidents, they can trigger a high level of stress among workers. Based on this logic, we can expect that foreign construction laborers in Korea will experience even more job stress due to language barriers and cultural differences. As job stress can have a negative impact on job performance, a plan to manage the job stress of foreign construction workers in Korea should be prepared to ensure successful construction projects. Thus, this study aims to probe the relationship between job stress and job satisfaction of foreign construction laborers in Korea using a decision tree. A survey was conducted after selecting factors of job stress, and an effect of each factor was analyzed using the decision tree. As a result of that, it was found that two factors, i.e. lack of reward and organizational system, were the main influential factors that affect the job satisfaction of foreign laborers. The findings of this research are expected to serve as fundamental data to improve job performance through job stress management of foreign workers in the future.
\end{abstract}

Keywords-Foreign laborer; Decision tree; Job stress; Job satisfaction

\section{INTRODUCTION}

As of 2012, there were 1,114,000 foreign workers in Korea. In particular, the construction industry employs 85,000 foreign laborers, which is almost 10 percent of the total population of foreign workers [1]. With the aging of Korean construction workers and the avoidance of " $3 \mathrm{D}$ " jobs by young job-seekers, the number of foreign workers in Korea has been on the rise. Moreover, an increase in foreign laborers employed in the Korean construction industry is seen by many as a good way to address the shortage of Korean construction laborers due to their relatively lower wage and easier employment.

The construction industry is labor-intensive, and to complete a project successfully, it is essential to provide a working environment that enables the construction laborers to concentrate fully on their jobs. But unlike other industries, construction laborers are more likely to get stressed due to high job intensity, the need to work on holidays, and the risk of safety accidents related with construction work [2]. Moreover, the foreign construction laborers in Korea may experience a different level of stress from Korean workers since the unfamiliar work setting, including the culture and the language, is greatly different from theirs.

The higher the job stress level, the lower the job satisfaction [3, 4, 5]. When job satisfaction is low, it turns out to have a negative impact on job performance [6]. Therefore, to improve the job performance of construction workers, it is important to understand the relationship between job stress and job satisfaction. In particular, with the number of foreign workers gradually increasing in the construction industry, it is especially important now to understand the relationship between job stress and job satisfaction of foreign construction workers. Studies have been conducted in the past on the relationship between stress and job satisfaction of foreign laborers [7, 8, 9, 10]. However, few studies have been conducted on foreign construction workers.

Therefore, this study aims to clarify the relationship between job stress and job satisfaction of foreign construction workers in Korea. To do this, we first identified factors of job stress and job satisfaction, and then conducted a survey on foreign construction workers. A decision tree analysis was then performed based on the survey results. Since the decision tree is expressed as a tree structure, it is easy to understand and interpret the results. Moreover, it is easy to understand the interaction between variables, because it shows how two or more variables are combined and affect the target variable, and is a nonparametric method that requires no assumption for linearity, normality or equal variance [11].

\section{THEORETICAL REVIEW}

\section{A. Foreign Laborers in Korea}

According to the '2012 Foreigner Labor Force Survey' reported by Statistics Korea in November 2012, a total of $1,114,000$ foreign laborers were found to be employed in all industries, accounting for 3.13 percent of all employees in Korea. Of the foreign workers, 85,000 or 7.63 percent were employed in the construction industry, indicating that a relatively high population of foreign workers is employed in the construction sector.

Table I indicates the "current state of foreign laborers by nationality.” Ethnic Korean in China and Chinese people were counted as 600,000 accounting for more than half of the entire population of foreign laborers. There are no official statistics for the construction industry, but the composition is expected to be similar. 
TABLE I

CURRENT STATE OF FOREIGN LABORERS BY NATIONALITY

\begin{tabular}{lcc}
\hline \multicolumn{1}{c}{ Nationality } & $\begin{array}{c}\text { Number of laborers } \\
\text { (thousand person) }\end{array}$ & $\begin{array}{c}\text { Composition } \\
\text { (\%) }\end{array}$ \\
\hline Total & 1,114 & 100 \\
Ethnic Korean in China & 457 & 41.0 \\
China & 143 & 12.8 \\
Vietnam & 114 & 10.2 \\
Uzbekistan & 31 & 2.8 \\
Philippines & 34 & 3.0 \\
Indonesia & 31 & 2.8 \\
Japan & 22 & 1.9 \\
Thailand & 24 & 2.1 \\
Mongolia & 21 & 1.8 \\
other Asian countries & 120 & 10.8 \\
North America (USA, Canada) & 81 & 7.3 \\
Europe & 22 & 2.0 \\
Oceania & 8 & 0.7 \\
Etc. & 8 & 0.7 \\
\hline
\end{tabular}

\section{B. Job Stress and Satisfaction}

Job stress is a harmful physical and emotional reaction in the body arising out of a disagreement between the capabilities or resources and needs [12]. Stress has both positive and negative effects on the worker's behaviors and attitudes. That is, an appropriate level of stress serves as an invigorator for mental and physical activities, and facilitates job performance; however, stress is shown to reduce job satisfaction in most laborers [13]. Job satisfaction refers to a work, and triggers voluntary initiatives, participation and creativity [15].

An excessive level of stress has negative effects such as anxiety and exhaustion, leading to a sharp decline in job performance [16]. Therefore, efforts should be made for a successful project. In other words, job stress factors of laborers should be studied to release the laborers' stress, increase job satisfaction and finally improve job performance [17].

\section{FACTORS OF JOB STRESS}

\section{A. Selecting factors of job stress}

To clarify the relationship between job stress and job satisfaction of foreign construction laborers, we selected factors of job stress first. Most of the job stress factors were adopted from Occupational Stress Scale for Korean Employees (KOSHA CODE H-42 2006) of the Korean Occupational Safety \& Health Agency, but some of the factors were added in consideration of the characteristics of foreign construction labors. That is, of the seven major factors of job stress in the measurement instrument ((1) job demand, (2) insufficient job control, (3) interpersonal conflict, (4) job insecurity, (5) organization system, (6) lack of reward, (7) occupational climate), factors (1) through (6) were included, and 'cooperation with foreign worker' was added (see Table II).

The factors of job satisfaction were not subdivided like

TABLE II. DETAIL OF THE QUESTIONNAIRE IN THIS STUDY

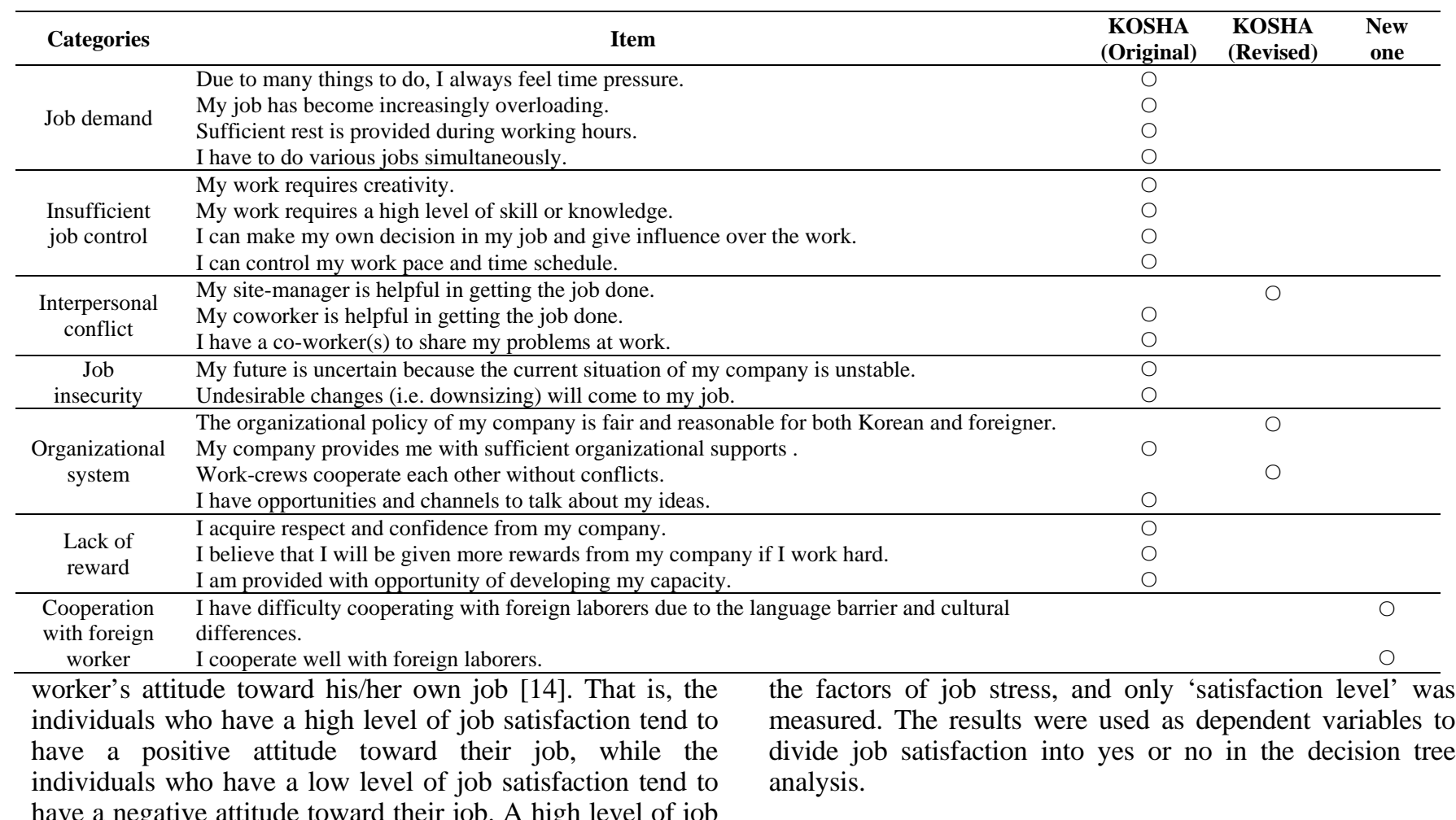




\section{B. Summary of Questionnaire}

A questionnaire survey of Korean and foreign construction laborers was conducted at 10 different construction sites in Gyeonggi region, and the survey was self-administered. The questionnaire was composed of 23 sub-items ( 22 job stress factors and 1 job satisfaction factor) and the sub-items were assessed using a 4-point Likert's scale (Never, Not very much, Moderately, Very much).

A total of 400 questionnaires were collected, and of them 375 questionnaires (183 from Koreans, 192 from foreigners) were used for the analysis. The summary of the respondents' information is shown as below in Table III.

TABLE III. SUMMARY OF QESTIONNAIRE RESPONDENTS

\begin{tabular}{cccc}
\hline Categories & $\begin{array}{c}\text { Number of } \\
\text { laborers } \\
\text { (person) }\end{array}$ & $\begin{array}{c}\text { percentage } \\
\mathbf{( \% )}\end{array}$ \\
\hline Nationality & Ethnic Korean in China & 183 & 48.8 \\
Age & Chinese & 96 & 25.6 \\
& 20s & 96 & 25.6 \\
& $30 \mathrm{~s}$ & 32 & 8.5 \\
Work & $40 \mathrm{~s}$ & 59 & 15.7 \\
experience & 50s & 148 & 39.5 \\
& 60s & 23 & 30.1 \\
& Under 5 years & 133 & 6.1 \\
& $6-10 y e a r s$ & 89 & 35.5 \\
& $11-15$ years & 87 & 23.7 \\
& 15-20 years & 29 & 23.2 \\
& More than 20years & 36 & 7.7 \\
\hline
\end{tabular}

C. Result of Questionnaire

The response values of the survey conducted for this study were scored using Equation (1) as suggested in the Occupational Stress Scale for Korean Employees of Korean Occupational Safety and Healthy Agency. A higher score indicates a higher level of stress.

$\frac{\text { (sum of score }- \text { number of question) }}{\text { (highest score }- \text { number of question) }} \times 100$

Table IV indicates the descriptive statistics of Korean and foreign laborers, difference in averages between the two groups, and the t-test results. First, the difference in averages 'lack of reward,' 'organizational system,' and 'insufficient job control.' In the t-test results, there was no significantly statistical difference between the two groups in the stress scores in two categories (job demand, and interpersonal conflict $)(\mathrm{p}<0.05)$.

\section{Decision Tree Analysis of Job Stress AND SATISFACTION}

A decision tree analysis was performed to investigate the relationship between job satisfaction and job stress. For the analysis, seven job stress factors were set as independent variables, while job satisfaction was set as a dependent variable. As the algorithm of the decision tree analysis, CART (Classification And Regression Test) was selected. 'Gini Index' was used as the splitting criterion because the dependent variable in this study is discrete. The maximum depth of the tree was set as ' 5 ' The stopping criteria was set as the minimum number of cases to be either top node ' 20 ' or bottom node ' 5 ' and the minimum variation of 'improvement' was set to be less than ' 0.0001 '

Through the decision tree analysis, Fig. 1 shows the decision trees of Korean and foreign construction workers. Risk estimate of the two models was ' 0.088 ' and ' 0.077 ' indicating that the accuracy of the two models is very high, and that the two models give a good explanation for the relationship between the job stress factors and job satisfaction.

The model for Korean workers was shown to be more complicated than the model for foreign workers, and more factors were used in the analysis, which means that the stress factors that affect the job satisfaction of foreign workers are simpler. To be more specific, five factors were found to affect job satisfaction of Korean workers, and from most important to least important these were 'interpersonal conflict,' 'organizational system,' 'lack of reward,' 'insufficient control,' and 'job insecurity.' On the other hand, two factors were found to affect job satisfaction of foreign workers, and in order of importance these were 'lack of reward,' and 'organizational system.' That is, if these factors are managed intensively, it is expected that the job satisfaction of foreign workers can be improved greatly.

TABLE IV. RESULT OF T-TEST FOR JOB STRESS AND SATISFACTION

\begin{tabular}{|c|c|c|c|c|c|c|c|}
\hline \multirow[b]{2}{*}{ Categories } & \multicolumn{2}{|c|}{ Korean laborer $(\mathrm{N}=183)$} & \multicolumn{2}{|c|}{ Foreign laborer $(\mathrm{N}=192)$} & \multirow{2}{*}{$\begin{array}{c}\text { Mean } \\
\text { difference } \\
\text { (A-B) }\end{array}$} & \multirow[b]{2}{*}{ t value } & \multirow[b]{2}{*}{ p value } \\
\hline & Mean (A) & $S D$ & Mean (B) & $S D$ & & & \\
\hline Job demand & 55.00 & 11.252 & 55.07 & 16.509 & -0.06 & -0.047 & 0.963 \\
\hline Insufficient job control & 50.31 & 13.085 & 56.81 & 17.648 & -6.49 & -4.033 & 0.000 \\
\hline Interpersonal conflict & 61.08 & 12.321 & 62.79 & 15.246 & -1.70 & -1.190 & 0.235 \\
\hline Job insecurity & 51.63 & 17.914 & 57.63 & 20.455 & -5.99 & -3.016 & 0.003 \\
\hline Organizational system & 56.01 & 13.202 & 63.54 & 16.721 & -7.53 & -4.826 & 0.000 \\
\hline Lack of reward & 53.37 & 14.618 & 60.93 & 17.206 & -7.56 & -4.580 & 0.000 \\
\hline Cooperation with foreign worker & 52.09 & 11.058 & 61.28 & 17.054 & -9.19 & -6.159 & 0.000 \\
\hline
\end{tabular}

between the two indicated that job stress level of foreign laborers is higher than that of Korean laborers in the overall categories. In particular, the difference was found to be highest for 'cooperation with foreign worker,' followed by 


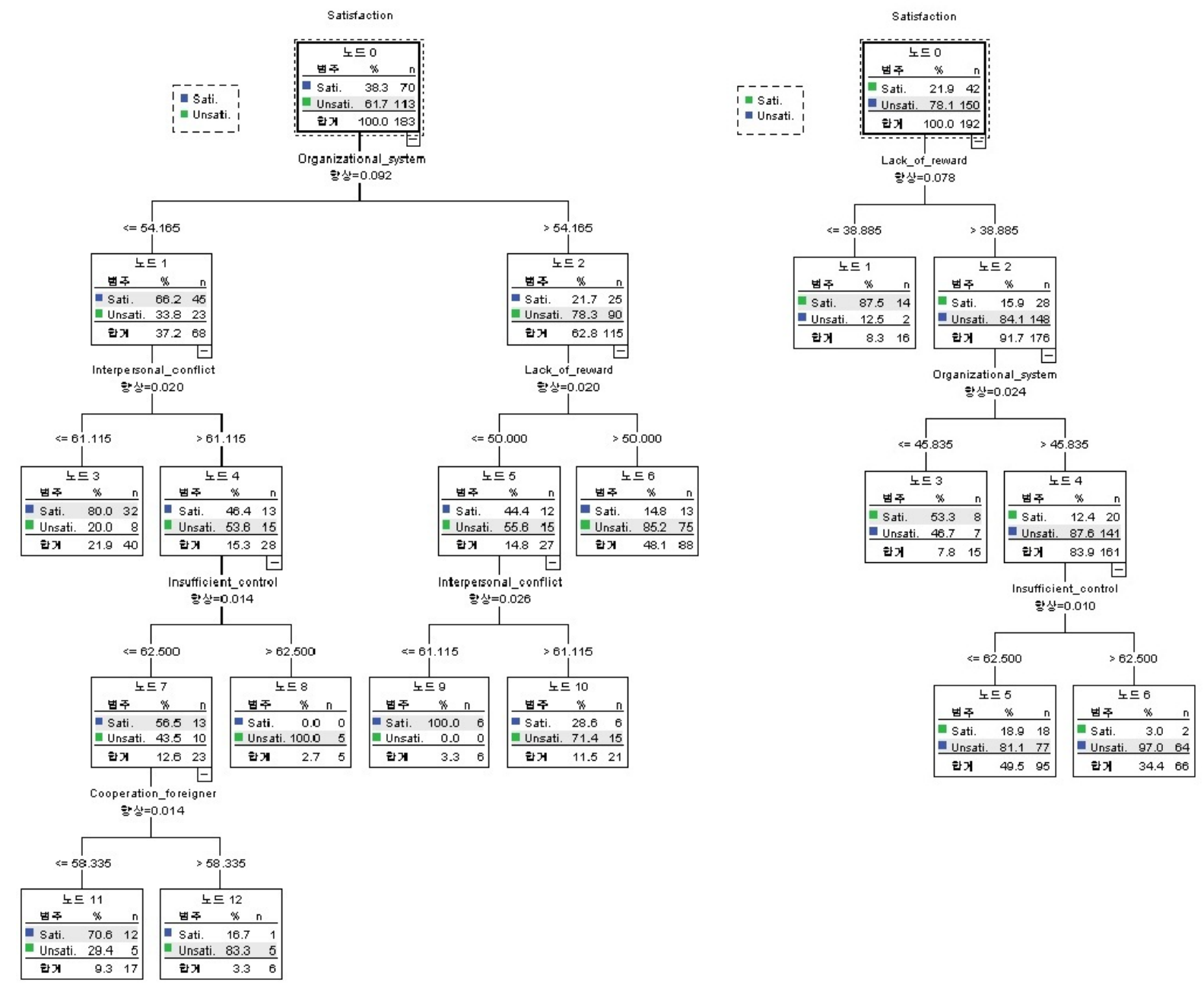

Figure 1. Decision tree model of Korean(left) and Foreign(right) laborer

\section{CONCLUSION}

The aging of Korean construction workers and the avoidance of the construction sector by young job-seekers have led to a shortage of construction workers, which is being addressed through the use of foreign laborers. Unlike other industrial sectors, the construction sector can trigger a high level of stress due to high job intensity and the risk of safety accidents, and it is expected that foreign workers will experience more stress because of the additional stress related to the language barrier and cultural differences. Job stress has been known to have a negative impact on job performance, and studies have been done to elucidate the relationship between the two. Despite this research, few studies have been conducted on job stress in foreign laborers working at construction sites in Korea. For this reason, this study aims to elucidate the relationship between job stress and job satisfaction of foreign construction laborers using a decision tree analysis. To do this, a questionnaire survey was conducted after factors of job stress and satisfaction were selected, based on which a decision tree analysis was performed. Through the analysis it was found that there were fewer factors that affected the job satisfaction of foreign laborers compared with the factors that affect the job satisfaction of Korean laborers, but the importance of the factors was shown to be higher. The findings of this study can be utilized in approaches to managing the job stress of foreign construction laborers in Korea.

The foreign laborers studied in this study were ethnic Koreans in China and Chinese people. While these two groups account for half of the foreign laborers in Korea, to get more general results a future study should consider foreign laborers with various nationalities, including laborers from the Philippines, Vietnam, and so on.

\section{ACKNOWLEDGMENT}

This research was supported by Basic Science Research Program through the National Research Foundation of Korea(NRF) funded by the Ministry of Education, Science and Technology(2012R1A1A1042693) 


\section{REFERENCES}

[1] Statistics Korea, “2012 Foreigner Labor Force Survey,” Press release of Statistics Korea, pp.1-46 November 2012.

[2] H. J. Choi, and H. G, Kwon, "The stress influences on the job attitudes toward the employees of construction industries," Korean Journal of Business Adminstration, Vol. 21, pp. 1723-1749 2008.

[3] G. R. Gemmill, W. J. Heisler, "Fatalism as a factor in managerial job satisfaction, job strain and mobility,” Personel Psychology, Vol. 25, pp. 241-250 June 1972.

[4] J. M. Ivancevich, M. T. Matteson, and E. P. Richard III, "Who's liable for stress on the job," Havard Business Review, Vol. 64, pp. 60-72. March 1985.

[5] D. H. Ahn, and M. J. Kang, "A Study on the Influence of Employee Job Stress on Job Satisfaction in the Travel Agency,” International Journal of Culture \& Tourism Research, Vol. 5, pp. 487-502 2003.

[6] M. Y. Leung, I. Y. S. Chan, and P. Olomolaiye, "Impact of stress on the performance of construction project managers," Journal of Construction Engineering and Management, Vol. 134, pp. 644-652 2008.

[7] J. H. Gwak, "A study on job satisfaction of alien workers in the construction industry," Master thesis, Seoul National University of Technology, 2006. 86 p.

[8] C. G. Jung, "An emperical study on the adjustment of foreign worker: its antecedents and effects on intention to leave a job," Master Thesis, SungkyunkwanUniversity, 2007. 143 p.
[9] M. H. Ban, "Stress of foreign workers in Korea," Master Thesis, Sungkyunkwan University, 2010. 66 p.

[10] Y. K. Lim, "A Study on the Causal Relationship between Stressor, Stress Symptoms, Deviant Behavior to foreign laborer in Korea,” The journal of social sciences, Vol. 26, pp. 185-207 2007.

[11] M. H. Huh, SPSS Statistics Classification Analysis, Datasolution Inc., Seoul: Korea, 2007.

[12] KOSHA, Asssessment and Management of Job Stress, Technical Report of Korea Occupational Safety and Health Agentcy, 2005.

[13] S. L. Kim, J. S. Jung, B. I. Lee, J. E. Lee, and K. Y. Rhee, "Fators related with job stastisfaction in wokers : Through the application of NIOSH job stress model," The Journal of Korean Community Nursing, Vol. 14, pp. 190-199 2003.

[14] S. K. Kim, Human Behavior in Organizations, Myungkyungsa, Seoul: Korea, 2002.

[15] Y. G. Shin, People Oriented Management, Dasanbooks, Seoul: Korea, 2005.

[16] H. B. Kim, H. Y. Moon, Y. W. Kwon, and H. W. Chang, "Downsizing Relationship on Job Stress and Job Satisfaction of Hotel Employees,” Journal of Korean Academic Society of Hospitality Administration, Vol. 13, pp. 65-80 2004.

[17] H. C. Oh, and S. Y. Jung, "A Study on the Casino Dealers' Job Stress and Job Satisfaction,” Journal of Tourism and Leisure Research, Vol. 19, pp. 255-274 2007. 